\title{
Familial Chilblain Lupus - A Monogenic Form of Cutaneous Lupus Erythematosus due to a Heterozygous Mutation in TREX1
}

\author{
C. Günther ${ }^{a} \quad$ M. Meurer ${ }^{a} \quad$ A. Stein ${ }^{a} \quad$ A. Viehweg ${ }^{a} \quad$ M.A. Lee-Kirsch ${ }^{b}$ \\ a University Hospital for Dermatology and ${ }^{b}$ University Hospital for Paediatric and Adolescent Medicine, \\ Technical University Dresden, Dresden, Germany
}

\section{Key Words \\ TREX1 gene - DNAse $\cdot$ Chilblain lupus . \\ Lupus erythematosus}

\begin{abstract}
Chilblain lupus erythematosus is a rare form of cutaneous lupus erythematosus characterized by bluish red infiltrates in acral locations of the body mostly affecting middleaged women. We recently described a familial form of chilblain lupus manifesting in early childhood caused by a heterozygous mutation in the TREX1 gene, which encodes a 3'-5' DNA exonuclease. Thus, familial chilblain lupus represents the first monogenic form of cutaneous lupus erythematosus. Here we describe the unusual clinical course of this newly defined genodermatosis in an 18-year-old female member of the family in which familial chilblain lupus was originally described. Copyright $\odot 2009$ S. Karger AG, Basel
\end{abstract}

\section{Introduction}

Chilblain lupus is a rare form of chronic cutaneous lupus erythematosus characterized by tender, bluish red swellings and nodules on acral surfaces such as the fin- gers, toes, heels, nose, ears and sometimes knees and elbows [1,2]. Chilblain lupus typically manifests itself during cold and damp times of the year or after a critical drop in temperature and is often difficult to distinguish clinically and histologically from true cold-induced chilblains [1, 3]. The presence of antinuclear antibodies and in few cases anti-Ro/SSA antibodies or rheumatoid factor as well as a positive lesional direct immunofluorescence are helpful to establish the diagnosis of chilblain lupus [4, 5] and to distinguish this form of lupus erythematosus from lupus pernio (cutaneous sarcoidosis) and acral vasculitis/vasculopathy due to cryoglobulinaemia.

Chilblain lupus usually occurs sporadically in middle-aged women and is rarely observed in children. We recently described a German family exhibiting an autosomal dominant form of chilblain lupus, which manifests itself in early childhood [6]. We mapped its genetic locus to chromosome $3 \mathrm{p}$ and subsequently identified a heterozygous mutation in the gene encoding the $3^{\prime}-5^{\prime}$ DNA exonuclease TREX1 affecting a highly conserved residue within the catalytic centre as the cause of familial chilblain lupus in this family $[6,7]$. Until to date, only 1 additional case of familial chilblain lupus caused by a mutation in the
TREX1 gene has been described in a pedigree of Bangladeshi origin [8]. During caspase-independent apoptosis initiated by granzyme A, TREX1 translocates into the nucleus and causes single-stranded DNA (ssDNA) damage by removing nucleotides from nicked 3 '-ends, thus reducing the possibility of repair by rejoining the nicked ends [9].

Mutations in TREX1 have been associated with a range of disorders with varying degrees of phenotypic overlap. These include Aicardi-Goutières syndrome, a rare infantile encephalopathy mimicking congenital viral infection characterized by basal ganglion calcification and chilblainlike lesions [10,11], autosomal dominant retinal vasculopathy with cerebral leukodystrophy [12] as well as systemic lupus erythematosus (SLE) [13]. While the molecular mechanisms underlying the diverse phenotypic spectrum of TREX1 mutations are not fully understood, functional analysis suggests a loss-of-function mechanism consistent with haplo-insufficiency $[7,10]$. In this report we provide a detailed description of the clinical course of a severely affected member from the German pedigree with familial chilblain lupus, in which this novel genodermatosis was originally described [6].

\section{KARGER}

Fax +4161306 1234 E-Mail karger@karger.ch www.karger.com
(C) 2009 S. Karger AG, Basel $1018-8665 / 09 / 2192-0162 \$ 26.00 / 0$

Accessible online at:

www.karger.com/drm
Claudia Günther, MD

University Hospital for Dermatology, Technical University Dresden

Fetscherstrasse 74, DE-01307 Dresden (Germany)

Tel. +49 351458 12947, Fax +49 3514585739

E-Mail claudia.guenther@uniklinikum-dresden.de 
1
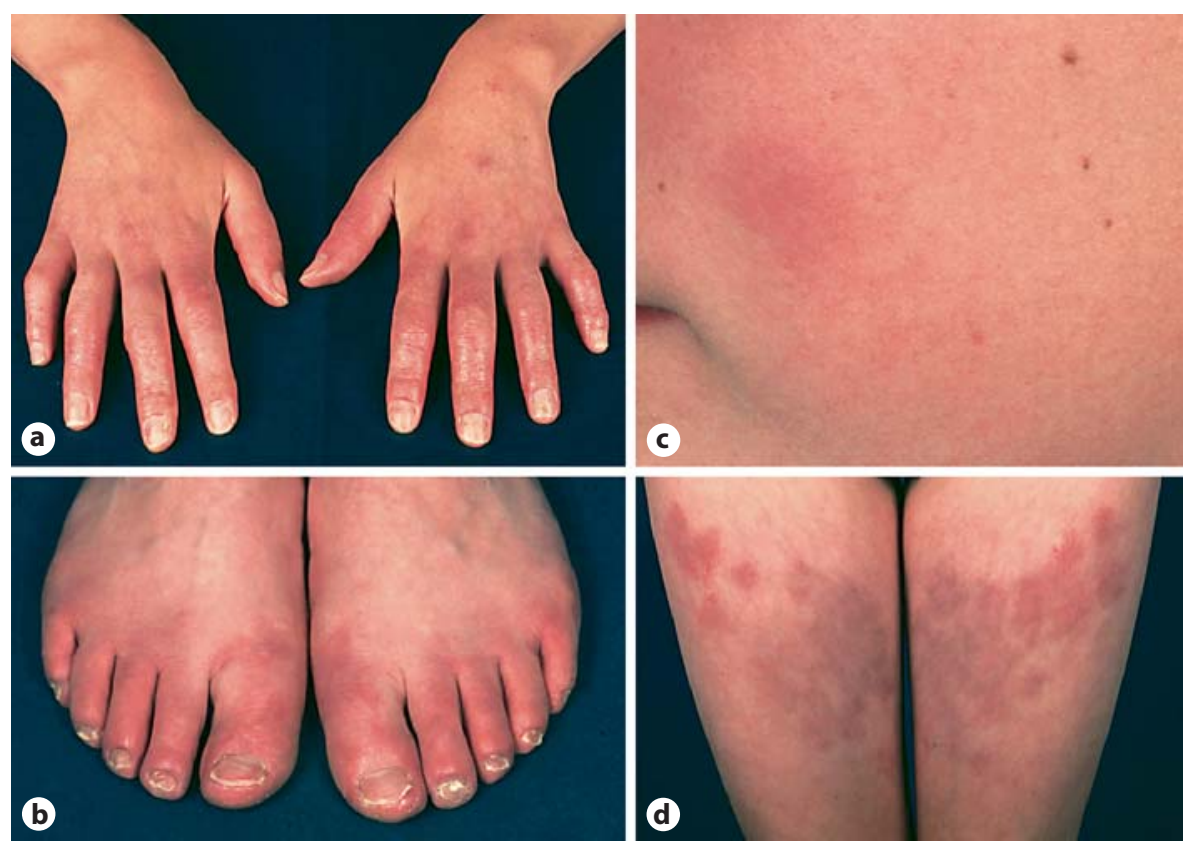

Fig. 1. Dermatological findings. Papular bluish red infiltrates on erythematous skin with fine white scaling extend on the dorsal sides of the fingers (a) and toes (b). Cutaneous lesions on the left cheek (c) and the thighs (d) appear as extended tender purple red subcutaneous infiltrates.

Fig. 2. Histology of lesional skin. a Biopsy from the finger showing vacuolar degeneration of basal keratinocytes, perivascular lymphocytic infiltration with partial alteration of the epidermal junction zone. Haematoxylin-eosin stain. Original magnification $\times 100$. b Biopsy from the thigh showing perivascular oedema and perivascular lymphocytic infiltration without epidermal involvement. Haematoxylin-eosin stain. Original magnification $\times 50$. c Alcian blue staining of the biopsy from the thigh reveals marked mucin deposition throughout the entire dermis extending to the subcutis. Original magnification $\times 50$.

\section{Case Report}

The patient presented at 2 years of age with painful bluish red infiltrates on her fingers which were precipitated by sudden temperature changes during the cold season. The cutaneous lesions resembled those seen in her mother and brother, who both experienced similar recurrent skin changes confined to fingers and toes since early childhood. At the age of 9 years, she was admitted to the hospital for the first time because of worsened skin lesions after swimming lessons at school. At this time her fingers and the rims of her soles were affected by tender plaquelike lividoid infiltrates. Apart from skin findings, her physical examination was unremarkable. Laboratory investigations revealed the presence of antinuclear antibodies with a titre of 1:160 and a homoge- neous pattern, reduced levels of complement C4 (0.18 g/l, normal range 0.2-0.49) and the presence of C3d-binding immune complexes. Anticardiolipin IgG and IgM as well as serum IgA and IgG were slightly elevated. There was no serological evidence for viral or bacterial infections. Tests for cryoglobulins and cryofibrinogen were negative, and all other laboratory values including complete blood cell count with differential, coagulation and liver function tests as well as urine analysis were within normal ranges. Nailfold capillary microscopy showed no pathological findings. Although a skin biopsy was not performed at that time, the diagnosis of cutaneous lupus erythematosus was suspected. Under stringent cold protection and skin care with urea-containing ointments, the patient experienced improvement of skin symptoms during
2
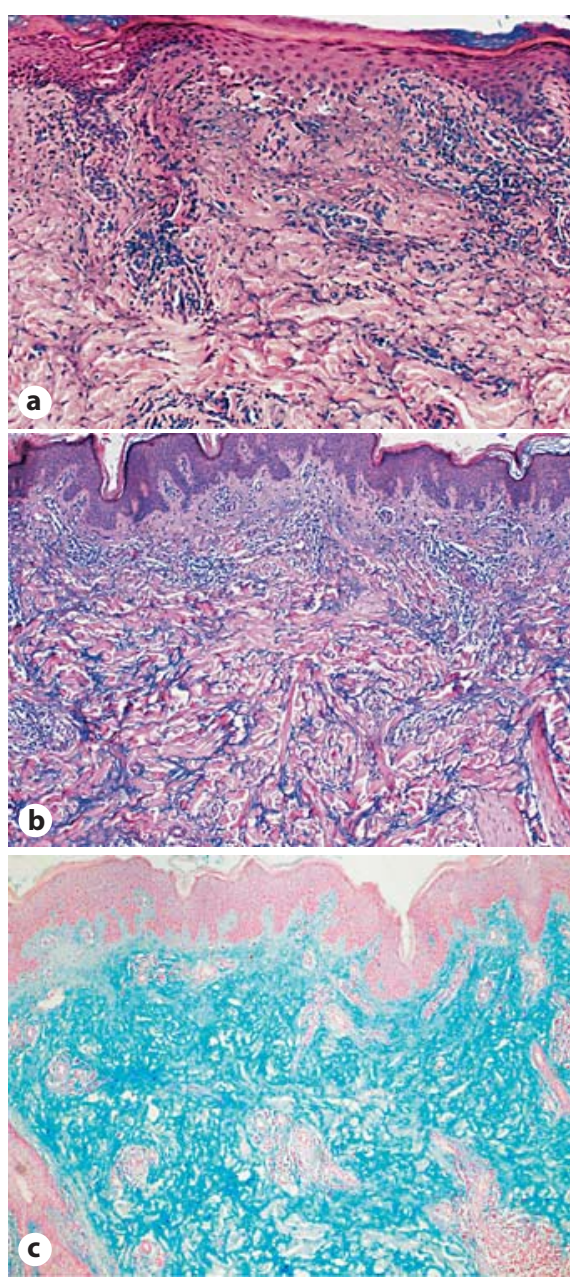

the following years until the age of 16, when she was hospitalized for anorexia and again suffered from a severe attack of erythematous skin lesions on fingers and toes.

At 18 years of age, she was referred to the hospital during late spring with bluish red infiltrates on erythematous skin partially covered with fine scales on the dorsal sides of fingers and toes (fig. 1). The fingernails were thickened with areas of yellow brownish discolouration and peripheral onycholysis. In addition, multiple tender subcutaneous erythematous infiltrates without epidermal alteration were seen on the thighs, buttocks, knees as well as on the left cheek (fig. 1). The lesions on the thighs were up to $4 \mathrm{~cm}$ in diameter and presented as deep, palpable infiltrations with a dark red to purple colour. Her complaints had increased during the last 4 
months during which she was under mental stress due to her final examinations at school. She did not complain of painful joints or tendons, palpitations, mental changes, hair loss, light sensitivity, oral ulcerations or gastro-intestinal problems typically seen in SLE.

Her body mass index was 17.9 (normal range: 18.4-25.2), and her blood pressure was 90 over $40 \mathrm{~mm} \mathrm{Hg}$. Apart from bradycardia with a heart rate of $44 / \mathrm{min}, \mathrm{ECG}$, echocardiography and abdominal ultrasound were without any pathological findings.

Histological examination of lesional skin from the finger showed a partially atrophic epidermis with vacuolar degeneration of basal keratinocytes (fig. 2a). Throughout the dermis, the vessel walls appeared swollen, and perivascular lymphocytic infiltrations with hydropic degeneration of the epidermal junction zone were seen. Alcian blue staining revealed marked deposition of mucin within the dermis. Epidermal findings in lesional skin from the thigh were rather discrete and included focal parakeratosis as well as follicular hyperkeratosis, while dermal changes were much more pronounced. Throughout the dermis extending to the upper subcutis, swollen vessel walls were surrounded by perivascular and periadnexal oedema as well as marked lymphocytic infiltrations (fig. 2b). Prominent deposits of mucin were present throughout the entire dermis and parts of the subcutis (fig. 2c). Direct immunofluorescence revealed band-like IgM and C3 depositions along the basement membrane zone on lesional skin from the finger and dorsal thigh (fig. 3a, b). Together, the histological findings were consistent with cutaneous lupus erythematosus of the fingers and plaque-like mucinosis of the thigh.

Laboratory examinations showed reduction of erythrocyte count of 3.77 cells/ $\mu l$ (normal range: 4.2-5.4) and a haematocrit of 0.34 (normal range: 0.37-0.47). Haemoglobin was within the normal range. Serum levels of IgA and IgG were slightly elevated. The concentration of complement C3 (0.91 g/l; normal: 0.9-1.8) and C4 (0.17 g/l; normal: 0.1-0.4) were within the lower range of normal. Complement C3c-, C3d- and C1q-binding immune complexes, anticardiolipin and antiphospholipid IgG and IgM antibodies were negative. A complete blood cell count with differential, kidney and liver function tests, protein electrophoresis as well
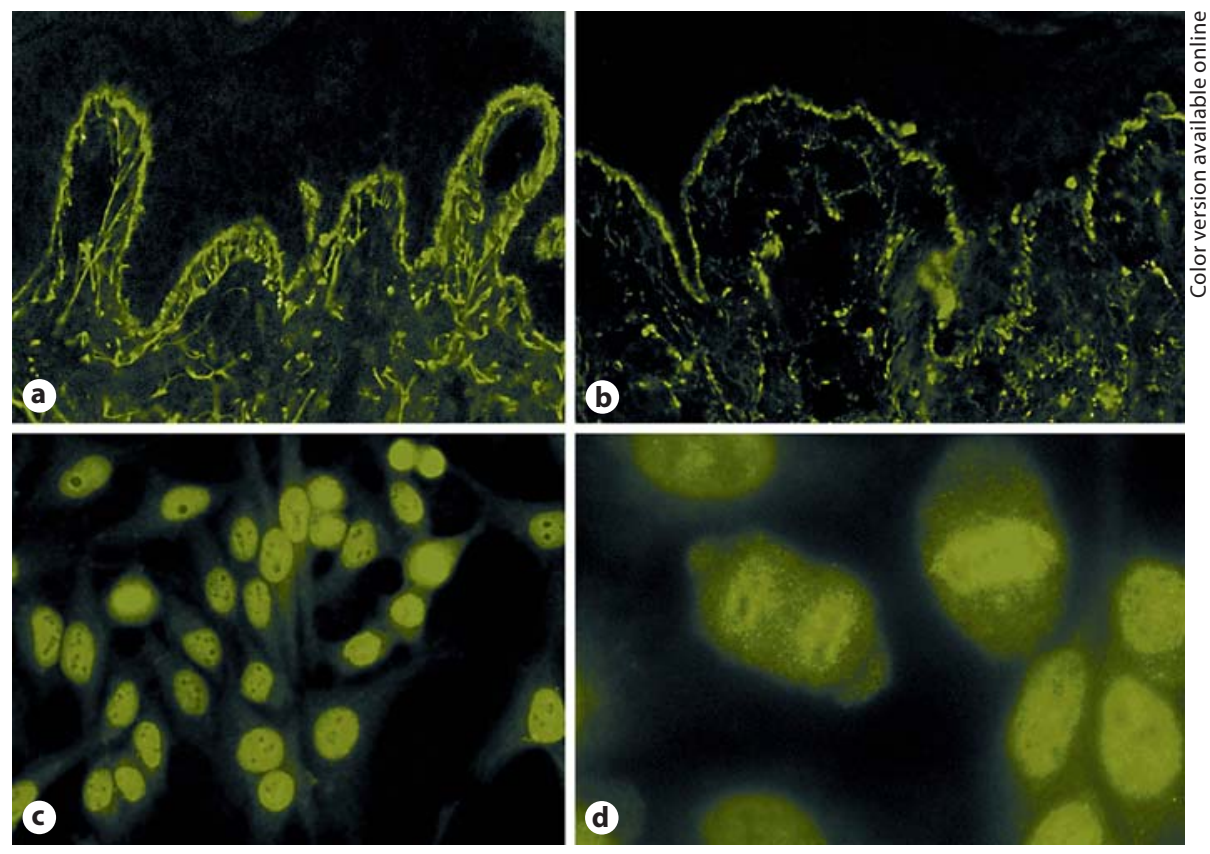

Fig. 3. Immunofluorescence. Direct immunofluorescence staining of lesional skin from the thigh (a) and finger (b) reveals band-like deposits of C3 in the dermal-epidermal junction zone. Indirect immunofluorescence using the patient's serum shows a homogeneous staining of the nucleoplasma of Hep-2 cells (c) as well as staining of chromatin of mitotic cells (d) along with a peculiar weak staining of the centre of chromatin.

as coagulation tests (Quick, partial thromboplastin time, international normalized ratio) were unremarkable. Cryoglobulins or cryofibrinogen were absent. A 24-hour urine status did not show increased protein or albumin levels. The patient HLA alleles were as follows: HLA-A1/A2, HLAB8/B44 (12), HLA-Bw6/Bw4, HLA-Cw7/ Cw7, HLA-DRB1 0301-0311 (DR3)/04010425 (DR4), HLA-DQB1 0201/0301.

Indirect immunofluorescence of Hep2 cells using the patient's serum showed a markedly elevated antinuclear antibody titre of 1:1,000 with homogeneous staining of nucleoplasma and chromosomes (fig. 3c, d). Auto-antibodies against Ro, La, nucleosomes, histones and doublestranded DNA were undetectable. However, auto-antibodies against ssDNA were weakly positive with $27 \mathrm{IU} / \mathrm{ml}$ ( $<25$ negative; 25-35 weakly positive, $>35 \mathrm{IU} / \mathrm{ml}$ positive). Interferon- $\alpha$ levels in serum were not increased. Nailfold capillary microscopy showed reduced capillary density with shape deformities such as elongation, partial grouping and dilatation on all fingers.
Based on the clinical, serological and histological findings, the diagnosis of chilblain lupus following the criteria of $\mathrm{Su}$ et al. [2] was confirmed. At this time several members of her family including her brother and mother had been diagnosed as having autosomal dominant familial chilblain lupus caused by a heterozygous mutation in the TREX1 gene. This mutation could also be confirmed in the case of the patient. Immunofluorescence staining of TREX1 of lesional skin revealed high expression of TREX1 in keratinocytes, endothelial and mononuclear cells. In comparison to normal skin, a slightly higher expression of TREX1 within the cytoplasm of keratinocytes was noted (fig. 4).

The patient had been on a low dose of $100 \mathrm{mg}$ acetylsalicylic acid (ASA) daily for the past 3 months prior to admission without clinical improvement. Due to her low blood pressure, therapy with the vasodilatory calcium channel blocker nifedipine was not considered initially. Instead, therapy with topical steroids and hydroxychloroquine at a low dose of $200 \mathrm{mg}$ daily was started. In addition, the patient was in- 

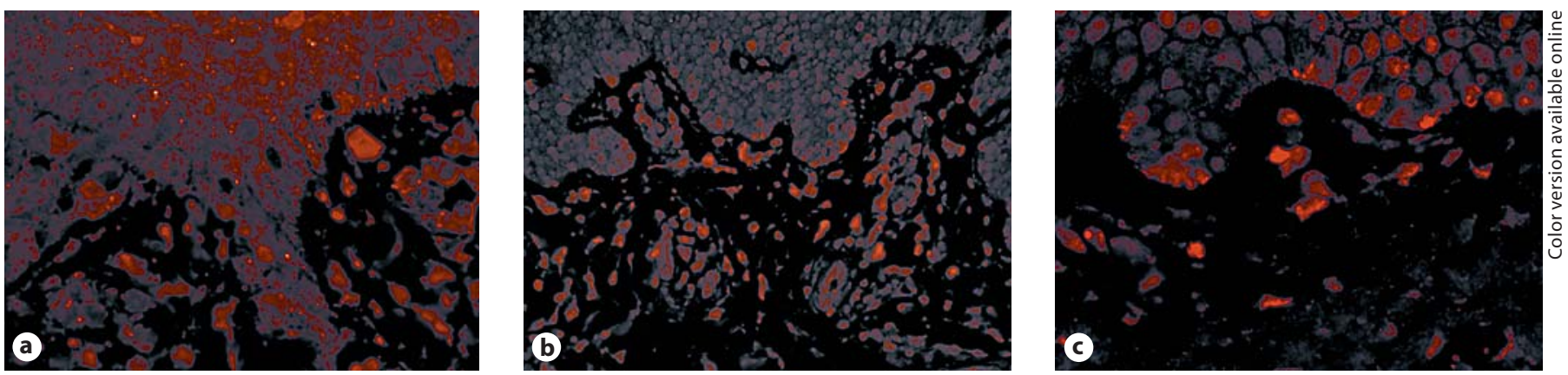

Fig. 4. Expression of TREX1. Lesional skin from the finger (a), thigh (b) and normal skin (c) was stained using mouse IgG1 antimouse TREX1 antibody (BD Transduction Laboratories) as primary and goat F(ab')2 anti-mouse IgG-AF546 antibody (Molecular Probes) as secondary antibody, respectively. TREX1 is strong- ly expressed within the cytoplasm of keratinocytes, vascular and mononuclear cells. In comparison to normal skin, TREX1 is more highly expressed in affected skin. Negative control sections without primary antibody were unstained (data not shown). Magnification $\times 400$. structed to prevent exposure to cold. Therapy was well tolerated, and after 4 months of treatment the clinical manifestations on her hands, feet and thighs had markedly improved. During the cold winter season, amlodipine $5 \mathrm{mg}$ daily was added to her medication. The drug was well tolerated and improved peripheral circulation. The cold-induced lesions appeared less lividoid, and heatable finger gloves prevented cold-induced ulcerations.

\section{Discussion}

The clinical presentation of this patient with chilblain lupus erythematosus is remarkable because of the extensive skin findings and the progressive course during adolescence, although the diagnostic criteria for SLE were formally never fulfilled. This is in contrast to the clinical presentation of other affected members of her family, in whom chilblain lesions tend to improve with age and progression to SLE has not been reported even in old age [6]. In addition to typical chilblain lesions in acral locations, the patient also presented with erythematous subcutaneous mucin-rich infiltrates without epidermal involvement on the thighs and the buttocks. This is reminiscent of LE tumidus lesions which are, however, usually smaller in size and located in sun-exposed areas [1]. Strong mucin deposition in nodular or papular form is rarely seen in discoid lupus erythematosus and occurs more frequently in patients with SLE accounting for about $2 \%$ of these cases $[14,15]$. In addi- tion, Jessner's lymphocytic infiltration of the skin has been recognized as a cutaneous form of lupus erythematosus that does not show epidermal involvement $[16,17]$.

The early onset of the disease can be explained by the genetic defect in the TREX1 gene identified in this family, although the exact molecular mechanisms that lead to chilblain lupus remain not fully understood. This mutation $[\mathrm{c} .52 \mathrm{G} \rightarrow \mathrm{A}$, leading to the substitution of an aspartate with an asparagine at position 18 of the TREX1 peptide (D18N)] affects a highly conserved residue within the catalytic centre of the TREX1 enzyme and has been shown to impair DNA damage during granzyme-A-mediated apoptosis $[6,7]$. Thus, this defect may be responsible for improper clearance of altered DNA causing intracellular accumulation of ssDNA, which in turn induces - through yet unidentified intracellular sensors and signalling pathways - an immune-mediated inflammatory response [7]. This is consistent with our finding of a strong expression of TREX1 in keratinocytes and vascular cells of the skin, the site of inflammation. Moreover, recent evidence suggests that intracellular accumulation of ssDNA in TREX1-deficient cells may be due to defects in the degradation of nucleic acids derived from chronic cell cycle checkpoint activation or from endogenous retroviruses $[18,19]$. This notion is supported by the finding of auto-antibodies against ssDNA in the patient's serum, albeit at low levels, which suggest an auto-immune response to ssDNA. In view of the fact that heterozygous carriers of TREX1 variants have a high risk for developing SLE [13], these findings underpin the importance of defects in intracellular nucleic acid metabolism for the pathogenesis of lupus erythematosus.

It is possible that additional permissive factors contributed to the clinical course in this patient. Thus, a low body mass index as well as pathological capillary changes observed in this patient may have played a role during exacerbation of chilblain lupus [20]. In fact, precipitation of chilblain lupus by anorexia in an adolescent male has recently been reported [21]. Because of the strong linkage disequilibrium of the HLA allele HLADRB10301 (HLA-DR3) and the C4 null allele, it is also possible that the low $\mathrm{C} 4$ levels in this patient are genetically determined [22]. C4 plays a critical role in the processing of immune complexes, and deficiency of $\mathrm{C} 4$ is known to confer susceptibility to SLE $[23,24]$.

The therapy of chilblain lupus primarily includes protection from cold [25] and improvement of the peripheral blood flow with ASA or nifedipine $[20,26]$. Topical steroids may be of benefit in some patients [27]. Hydroxychloroquine has been used with inconsistent success [3] and usually requires continued treatment throughout the warm season $[2,27]$. The therapeutic effect of other immunosuppressive drugs such as cyclophosphamide or mycophenolate mofetil has been reported in single cases only [21]. In the present case bloodflow-enhancing intervention with ASA was not helpful, while treatment with hydroxychloroquine was highly effective. 
Taken together, the present case provides a detailed description of the unusual clinical course of a patient with familial chilblain lupus due to a mutation in TREX1 by demonstrating a rather progressive

\section{References}

1 Kuhn A, Sticherling M, Bonsmann G: Clinical manifestations of cutaneous lupus erythematosus. J Dtsch Dermatol Ges 2007;5: 1124-1137.

2 Su WP, Perniciaro C, Rogers RS III, White JW Jr: Chilblain lupus erythematosus (lupus pernio): clinical review of the Mayo Clinic experience and proposal of diagnostic criteria. Cutis 1994;54:395-399.

3 Bouaziz JD, Barete S, Le PF, Amoura Z, Piette JC, Frances C: Cutaneous lesions of the digits in systemic lupus erythematosus: 50 cases. Lupus 2007;16:163-167.

4 Allegue F, Alonso ML, Rocamora A, Ledo A: Chilblain lupus erythematosus and antiphospholipid antibody syndrome. J Am Acad Dermatol 1988;19:908-910.

5 Franceschini F, Calzavara-Pinton P, Valsecchi L, Quinzanini M, Zane C, Facchetti F, Airo P, Cattaneo R: Chilblain lupus erythematosus is associated with antibodies to SSA/Ro. Adv Exp Med Biol 1999;455:167171.

6 Lee-Kirsch MA, Gong M, SchulzH, Ruschendorf F, Stein A, Pfeiffer C, Ballarini A, Gahr M, Hubner N, Linne M: Familial chilblain lupus, a monogenic form of cutaneous lupus erythematosus, maps to chromosome $3 \mathrm{p}$. Am J Hum Genet 2006;79:731-737.

7 Lee-Kirsch MA, Chowdhury D, Harvey S, Gong M, Senenko L, Engel K, Pfeiffer C, Hollis T, Gahr M, Perrino FW, Lieberman J, Hubner N: A mutation in TREX1 that impairs susceptibility to granzyme A-mediated cell death underlies familial chilblain lupus. J Mol Med 2007;85:531-537.

8 Rice G, Newman WG, Dean J, Patrick T, Parmar R, Flintoff K, Robins P, Harvey S, Hollis T, O'Hara A, Herrick AL, Bowden AP, Perrino FW, Lindahl T, Barnes DE, Crow YC: Heterozygous mutations in TREX1 cause familial chilblain lupus and dominant Aicardi-Goutieres syndrome. Am J Hum Genet 2007;80:811-815.

9 Chowdhury D, Beresford PJ, Zhu P, Zhang D, Sung JS, Demple B, Perrino FW, Lieberman $\mathrm{J}$ : The exonuclease TREX1 is in the SET complex and acts in concert with NM23-H1 to degrade DNA during granzyme A-mediated cell death. Mol Cell 2006;23:133-142. course with extended dermatological findings. In addition, this case indicates that hydroxychloroquine may be an efficient therapeutic option for severe cases of familial chilblain lupus.

\section{Acknowledgements}

We thank Nick Zimmermann for technical assistance. The study was funded by a MeDDrive grant 2009 to C.G. and a DFG grant (1074/3-1) to M.L.K.
10 Crow YJ, Hayward BE, Parmar R, Robins P, Leitch A, Ali M, Black DN, van Bokhoven $\mathrm{H}$, Brunner HG, Hamel BC, Corry PC, Cowan FM, Frints SG, Klepper J, Livingston JH, Lynch SA, Massey RF, Meritet JF, Michaud JL, Ponsot G, Voit T, Lebon P, Bonthron DT, Jackson AP, Barnes DE, Lindahlet T: Mutations in the gene encoding the $3^{\prime}-5^{\prime}$ DNA exonuclease TREX1 cause Aicardi-Goutieres syndrome at the AGS1 locus. Nat Genet 2006;38:917-920.

11 Kolivras A, Aeby A, Crow YJ, Rice GI, Sass U, Andre J: Cutaneous histopathological findings of Aicardi-Goutieres syndrome, overlap with chilblain lupus. J Cutan Pathol 2008;35:774-778.

12 Richards A, van den Maagdenberg AM, Jen JC, Kavanagh D, Bertram P, Spitzer D, Liszewski MK, Barilla-Labarca ML, Terwind GM, Kasai Y, McLellan M, Grand MG, Vanmolkot KR, de Vries B, Wan J, Kane MJ, Mamsa H, Schafer R, Stam AH, Haan J, de Jong PT, Storimans CW, van Schooneveld MJ, Oosterhuis JA, Gschwendter A, Dichgans M, Kotschet KE, Hodgkinson S, Hardy TA, Delatycki MB, Hajj-Ali RA, Kothari PH, Nelson SF, Frants RR, Baloh RW, Ferrari $\mathrm{MD}$, Atkinsonet JP: C-terminal truncations in human $3^{\prime}-5^{\prime}$ DNA exonuclease TREX1 cause autosomal dominant retinal vasculopathy with cerebral leukodystrophy. Nat Genet 2007;39:1068-1070.

13 Lee-Kirsch MA, Gong M, Chowdhury D, Senenko L, Engel K, Lee YA, de Silva U, Bailey SL, Witte T, Vyse TJ, Kere J, Pfeiffer C, Harvey S, Wong A, Koskenmies S, Hummel O, Rohde K, Schmidt RE, Dominiczak AF, Gahr M, Hollis T, Perrino FW, Lieberman J, Hubner N: Mutations in the gene encoding the $3^{\prime}-5$ ' DNA exonuclease TREX1 are associated with systemic lupus erythematosus. Nat Genet 2007;39:1065-1067.

14 Kanda N, Tsuchida T, Watanabe T, Tamaki $\mathrm{K}$ : Cutaneous lupus mucinosis: a review of our cases and the possible pathogenesis. J Cutan Pathol 1997;24:553-558.

15 Weigand DA, Burgdorf WH, Gregg LJ: Dermal mucinosis in discoid lupus erythematosus: report of two cases. Arch Dermatol 1981; 117:735-738.
16 Lipsker D: Classification of specific cutaneous manifestations in patients with lupus erythematosus: a time for change? The concept of dermal lupus erythematosus. Dermatology 2006;212:324-326.

17 Lipsker D, Mitschler A, Grosshans E, Cribier B: Could Jessner's lymphocytic infiltrate of the skin be a dermal variant of lupus erythematosus? An analysis of 210 cases. Dermatology 2006;213:15-22.

18 Yang YG, Lindahl T, Barnes DE: Trex1 exonuclease degrades ssDNA to prevent chronic checkpoint activation and autoimmune disease. Cell 2007;131:873-886.

19 Medzhitov R, Janeway CA Jr: Innate immunity: the virtues of a nonclonal system of recognition. Cell 1997;91:295-298.

20 Doutre MS, Beylot C, Beylot J, Pompougnac E, Royer P: Chilblain lupus erythematosus: report of 15 cases. Dermatology 1992;184: 26-28.

21 Hedrich CM, Fiebig B, Hauck FH, Sallmann S, Hahn G, Pfeiffer C, Heubner G, LeeKirsch MA, Gahr M: Chilblain lupus erythematosus - a review of literature. Clin Rheumatol 2008;27:949-954.

22 Dorak MT, Shao W, Machulla HK, Lobashevsky ES, Tang J, Park MH, Kaslow RA: Conserved extended haplotypes of the major histocompatibility complex: further characterization. Genes Immun 2006;7:450-467.

23 Tsao BP: Update on human systemic lupus erythematosus genetics. Curr Opin Rheumatol 2004;16:513-521.

24 Agnello V, Gell J, Tye MJ: Partial genetic deficiency of the $\mathrm{C} 4$ component of complement in discoid lupus erythematosus and urticaria/angioedema. J Am Acad Dermatol 1983;9: 894-898.

25 Uter W, Proksch E, Schauder S: Chilblain lupus erythematosus. Hautarzt 1988;39:602605 .

26 Rustin MH, Newton JA, Smith NP, Dowd PM: The treatment of chilblains with nifedipine: the results of a pilot study, a doubleblind placebo-controlled randomized study and a long-term open trial. Br J Dermatol 1989;120:267-275

27 Millard LG, Rowell NR: Chilblain lupus erythematosus (Hutchinson): a clinical and laboratory study of 17 patients. Br J Dermatol 1978;98:497-506 